\title{
Effective long-term treatment of obesity: a continuing care model
}

\author{
JD Latner ${ }^{1 *}$, AJ Stunkard ${ }^{2}$, GT Wilson ${ }^{1}$, ML Jackson ${ }^{3}$, DS Zelitch ${ }^{3 \dagger}$ and E Labouvie $^{1}$ \\ ${ }^{1}$ Department of Psychology, Rutgers University, Piscataway, NJ, USA; ${ }^{2}$ Department of Psychiatry, University of Pennsylvania, \\ Philadelphia, PA, USA; and ${ }^{3}$ Trevose Behavior Modification Program, Trevose, PA, USA
}

\begin{abstract}
BACKGROUND: Despite the well-documented success of behavioral techniques in producing temporary weight loss, treatment is typically followed by weight regain. The maintenance of treatment effects may therefore be the greatest challenge in the long-term management of obesity, and continuous care may be necessary to achieve it.

OBJECTIVE: To describe the design and evaluate the effectiveness of the Trevose Behavior Modification Program, a potentially widely replicable self-help weight loss program offering continuous care.

DESIGN: A description of the course of all subjects $(n=171)$ who entered the Trevose program during 1992 and 1993. SUBJECTS: One hundred and forty-six women aged $44.1 \pm 11.7 \mathrm{y}$ with a body mass index $\left(\mathrm{BMI}, \mathrm{kg} / \mathrm{m}^{2}\right) \mathrm{of} 33.2 \pm 4.4$, and 25 men aged 49.0 \pm 19.6 with a BMI of 35.1 \pm 5.2 enrolled in the Trevose program during 1992-1993.

RESULTS: Mean duration of treatment was 27.1 months, with $47.4 \%$ of members still in treatment at $2 \mathrm{y}$ and $21.6 \%$ at 5 y. Mean intent-to-treat weight loss was $13.7 \pm 0.5 \%$ of initial weight, or $12.8 \pm 0.5 \mathbf{k g}$. As long as they remained in treatment, almost all participants lost at least $5 \%$ of their initial weight and at least $83 \%$ lost more than $10 \%$. Members completing $2 y$ of treatment lost an average of $19.3 \%$ of their initial body weight $(17.9 \mathrm{~kg})$; at $5 \mathrm{y}$ the loss was still $17.3 \%$ $(15.7 \mathrm{~kg})$. After leaving the program, subjects regained weight but remained $4.7 \%(4.5 \mathrm{~kg})$ below their pretreatment weight.

CONCLUSION: A low-cost program offering treatment of indefinite duration produced large long-term weight losses and may be suitable for widespread replication.

International Journal of Obesity (2000) 24, 893-898
\end{abstract}

Keywords: weight loss; weight maintenance; continuing care; self help

\section{Introduction}

The overarching problem in the treatment of obesity is the consistency with which weight lost in treatment is regained. This problem has led to the view that obesity is a chronic disorder which requires longterm treatment. ${ }^{1}$ The two forms of treatment are pharmacologic and behavioral. In 1997, the appearance of valvular heart disease in a significant number of persons who took dexfenfluramine in combination with phentermine, after years of apparently safe use of DL-fenfluramine, raised concern over the long-term use of any medication. ${ }^{2,3}$ The advent of two apparently safer medications, sibutramine and orlistat, promises only modest weight losses, and their long term safety and effectiveness still need to be established. Since medication for obesity must be administered by physicians on an individual basis, its effect on the

*Correspondence: JD Latner, Department of Psychology, Rutgers University, 152 Frelinghuysen Road, Piscataway, NJ 08854-8020, USA.

E-mail: jlatner@rci.rutgers.edu

$\dagger$ This work is dedicated to the memory of David Zelitch (19241998), whose leadership and abilities through decades of devotion have made the Trevose Behavior Modification Program and this research possible.

Received 21 June 1999; revised 9 November 1999; accepted

9 February 2000 general population may be limited. ${ }^{4}$ Behavioral programs for the control of obesity have potential for more widespread use, but evidence of their long-term effectiveness is also limited. In six studies with follow-up periods of at least $4 \mathrm{y}$, the mean weight at follow-up was only $1.9 \mathrm{~kg}$ lower than at the beginning of treatment. ${ }^{5-10}$

Two reports indicate that long-term weight losses can be achieved. The first report described a register of more than 1000 persons from all parts of the US who maintained large weight losses for a period of years. ${ }^{11}$ These subjects reported that their success was due to continuing implementation of strategies that are core elements of behavioral treatment programs: selfmonitoring of food intake and physical activity, weekly weighing, better nutrition, and exercise. The second report described the only program that continued treatment for as long as $4 \mathrm{y} .{ }^{12} \mathrm{In}$ this Swedish study of 104 severely obese (body mass index, $\mathrm{BMI}=41.5 \mathrm{y})$ persons ( 81 women and $26 \mathrm{men}$ ), $69 \%$ remained in treatment for $4 \mathrm{y}$ and lost an average of $11.7 \mathrm{~kg}$. During this time, behavioral measures were employed initially on a weekly basis and subsequently less frequently. Any increase in weight led to reinstitution of more intensive outpatient therapy and, if that failed, to inpatient therapy. Ten to twelve year follow-up data indicated a maintenance of weight losses averaging $10.5 \mathrm{~kg} .{ }^{13}$ 
These rare successes suggesting the importance of treatment duration are supported by a meta-analysis that found that treatment duration was significantly correlated with weight loss after treatment and at follow-up. ${ }^{14}$ Another study showed that 40 weeks of treatment produced significantly greater weight losses than did 20 weeks, both at 40 weeks $(13.6$ vs $6.4 \mathrm{~kg})$ and at 72 weeks $(9.9$ vs $4.6 \mathrm{~kg})$ after the start of treatment. ${ }^{15}$

These studies suggest two causes of the poor longterm results of treatment of obesity. The first is inadequate implementation (rather than inadequate techniques). The second is inadequate duration of treatment. We report here an effective behavioral treatment program of long duration, with costs so low that it can be widely replicated and can serve as a model of continuing care.

\section{Methods}

The Trevose Behavior Modification Program was begun in 1970 by David Zelitch, a formerly obese man, as a means of helping himself maintain his weight loss. The program now treats approximately 1000 persons in its central location and in 63 smaller satellite groups in Philadelphia and its surrounding areas. It is lay-directed and lay-administered, staffed entirely by volunteers and it charges no fees. The Trevose Program has been operating in its present form for more than $25 \mathrm{y}$ and has earned recognition by other weight loss programs in the Philadelphia area for its willingness to accept all patients refused treatment by them, usually for lack of funds.

Like most behavioral programs, the Trevose program involves standard techniques, delivered in weekly $1 \mathrm{~h}$ meetings of groups of about 10 persons. It includes weigh-ins, self-monitoring of food intake and physical activity, measures to slow the rate of eating, and social support. Subjects are weighed at each of the weekly meetings on a balance-beam scale.

The first step in the program is selection of the applicant's weight loss goal. Goals are derived from the 1959 tables of the Metropolitan Life Insurance Company ${ }^{16}$ and are subject to two constraints: they must be within the range of normal weight and no less than 20 nor more than 100 pounds less than the applicant's initial body weight. This latter constraint excludes very obese persons with their poorer prognosis as well as persons with solely cosmetic concerns. Once the overall goal is set, monthly weight loss goals are established, based on a cumulative percentage of the overall goal.

Unlike most behavior therapy programs, attendance and achieving weight loss goals are strictly enforced. A critical part of the program is a 5-week trial of treatment. During this time attendance is mandatory, as is the loss of $15 \%$ of the total weight loss goal; only those meeting these requirements are accepted as full members. Thereafter the cumulative weight loss goals are $22 \%$ of the total goal for the second month, $30 \%$ for the third month, and so forth until $90 \%$ of the goal is achieved. After the first 5 weeks, absences may be excused, but only with 2 weeks advance notice. During vacations, members must mail a record of their weight to their group leader on the day of their usual meeting. Failure to meet attendance or weight loss requirements during the first 4 months results in immediate dismissal from the program. After 4 months, members who fail to meet a weight loss requirement are given a grace period of one month ('drop-out') or 2 months ('parole') in which to lose the required weight, but once again, failure results in dismissal.

When members have reached, and maintained, their weight loss goal for 4 months, the requirement for attendance drops to two meetings a month and, after 8 months, to one meeting a month. After 12 months of successful maintenance, members are graduated to 'independence level' and are not required to attend meetings. About $10 \%$ choose to continue regular attendance and they form the pool from which new group leaders are chosen. Those who do not continue to attend must keep weight records and mail them in to their group leader monthly. A weight gain of up to 10 pounds (above their weight when they reached 'independence level') triggers an urgent request for the member to return for weekly meetings until the extra weight is lost. If, however, the gain is greater than 10 pounds, the members are not allowed to rejoin the program until their weight is no more than 10 pounds above their 'independence level' weight.

This report describes the outcome of all subjects enrolled in the Trevose program during the years 1992-1993. Information on these individuals included gender, age on entry into the program, initial weight, BMI, weight loss goal and weights recorded monthly during treatment. Participant flow during the study is shown in Figure 1.

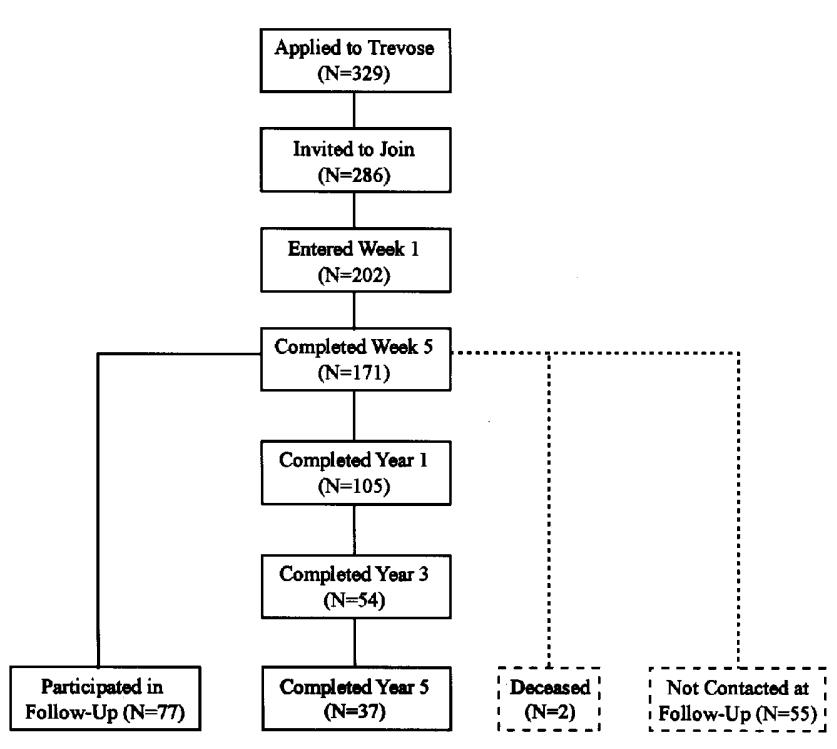

Figure 1 Participant flow during the study. 
A total of 134 of 171 persons who were full members of the 1992-1993 cohort dropped out during the $5 \mathrm{y}$ of membership in the program. Reported current weight was obtained from 77 $(58 \%)$ of these drop-outs through telephone contact, which took place an average of 47.1 months after they had left the program. This study was approved by the Rutgers University Institutional Review Board.

\section{Statistical analysis}

The most important aspect of this study is the long duration of treatment (Figure 2). There is no standard way of displaying the weight loss data of persons who remain in a program for long, and varying, periods of time. Accordingly, we devised a method, depicted in Figure 3, that shows the weight loss of participants who remained in the program for designated periods of time. The weight loss curves include subjects who reached the designated cut-off points $(6,12,24,30$ and 60 months). Weights of participants who remained in the program beyond a cut-off point but did not reach the next cut-off point are shown until the earlier cut-off point (ie weights of members remaining in the program between 36 and 59 months are depicted through the 36 th month of participation).

Regression analyses were used to estimate predictors of weight loss.

\section{Results}

Figure 1 shows the course of the 329 persons who applied to Trevose in 1992-1993. Of these, 202 (169

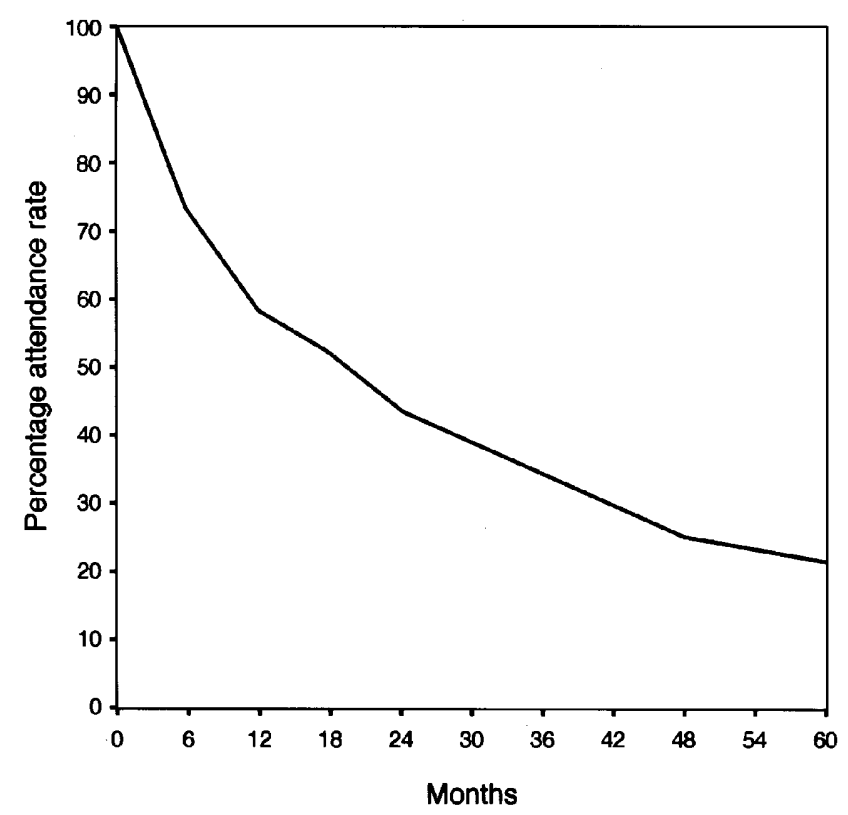

Figure 2 Decrease in the percent of members attending the Trevose Behavior Modification Program during the $5 \mathrm{y}$ study period. $100 \%$ consists of full members who had completed the 5 week trial period. See text for explanation. women and 33 men) entered the 5-week trial which was completed by 171 (146 women and $25 \mathrm{men}$ ), who became full members. Ages of female and male full members were $44.1 \pm 11.7$ and $49.0 \pm 10.6$, respectively, and their BMIs were 33.2 44.4 and 35.1 \pm 5.2.

Mean duration of treatment was 27.1 months. Figure 2 shows the percentage of full members continuing in the program: $61.4 \%$ at $1 \mathrm{y}, 47.4 \%$ at $2 \mathrm{y}$ and $21.6 \%$ at $5 \mathrm{y}$.

Mean intent-to-treat weight loss for all full members was $13.7 \pm 0.5 \%$ of initial weight or $12.8 \pm 0.5 \mathrm{~kg}$. (Percentage weight loss and $\mathrm{kg}$ of weight loss are quite similar for all measurements.) The percentage of members who lost $5 \%$ and $10 \%$ of their initial body weight is depicted in Table 1. As long as they were in the program, almost all participants lost at least $5 \%$ of their initial weight and at least $83 \%$ had lost $10 \%$ or more.

Figure 3 illustrates this critical aspect of the Trevose program - the maintenance of weight losses of persons as long as they remain in the program. It depicts the weight losses of members who remained in the program for varying periods of time: $6,12,24,36$ and 60 months. The $61.4 \%$ of the full members who remained in treatment at $1 \mathrm{y}$ lost $18.5 \%$ of their original weight $(17.1 \mathrm{~kg})$, and the $47.4 \%$ who remained at $2 \mathrm{y}$ lost $19.3 \%$ of their original weight $(17.9 \mathrm{~kg})$. At $5 \mathrm{y}$, weight loss of members remaining in treatment averaged $17.3 \%$ of original weight $(15.7 \mathrm{~kg})$. The percentages are of all full members,

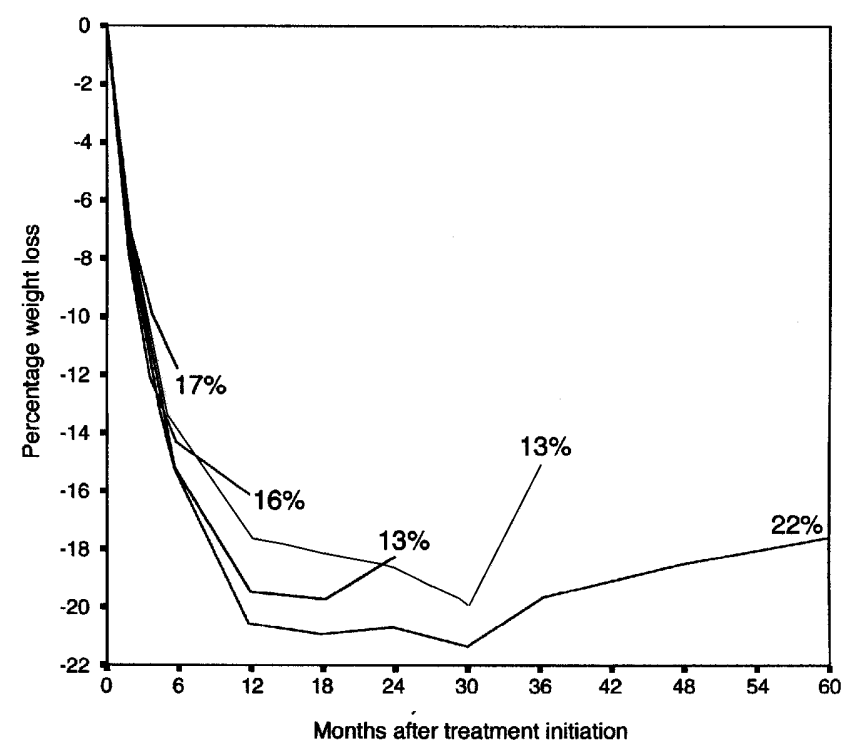

Figure 3 Weight losses of full members who remained in the program for varying periods of time. The curves show the weight losses of members who completed varying durations of treatment: $6,12,24,36$ and 60 months. The percentages refer to the percent of all full members who reached these cut-off points. For example, at 60 months, $22 \%$ were still in treatment and had lost $17 \%$ of their initial weight. This method of presentation is conservative, since it does not depict weight losses between cutoff points, for persons who remained in the program beyond one cut-off point but did not reach the next cut-off point. The figure does not include the $20 \%$ of full members who dropped out of treatment during the first 6 months. Numbers in the figure have been rounded. 
Table 1 Mean weight loss of Trevose and Orlistat subjects at 6, 12, 24, 36, 48 and 60 months and those achieving weight losses of $5 \%$ or more and $10 \%$ or more of initial body weight

\begin{tabular}{|c|c|c|c|c|c|c|c|c|c|c|c|c|}
\hline \multirow[b]{3}{*}{ Months } & & & \multicolumn{3}{|c|}{ Mean Percentage loss } & \multicolumn{3}{|c|}{$5 \%$ loss } & \multicolumn{3}{|c|}{$10 \%$ loss } & \multirow{3}{*}{$\begin{array}{c}\text { Mean } \\
\text { weight } \\
\text { loss (kg) } \\
\text { Trevose }\end{array}$} \\
\hline & \multicolumn{2}{|c|}{$n$} & & \multicolumn{2}{|c|}{ Orlistat } & \multirow[b]{2}{*}{ Trevose } & \multicolumn{2}{|c|}{ Orlistat } & \multirow[b]{2}{*}{ Trevose } & \multicolumn{2}{|c|}{ Orlistat } & \\
\hline & Trevose & Orlistat & Trevose & Drug & Placebo & & Drug & Placebo & & Drug & Placebo & \\
\hline 0 & 171 & 880 & - & - & - & - & - & - & - & - & - & - \\
\hline 6 & 136 & - & 14 & - & - & 98 & - & - & 85 & - & - & 13 \\
\hline 12 & 105 & 591 & 19 & 9 & 6 & 99 & 66 & 44 & 97 & 39 & 25 & 17 \\
\hline 24 & 81 & 403 & 19 & 8 & 5 & 100 & 39 & 25 & 94 & 34 & 18 & 18 \\
\hline 36 & 59 & - & 18 & - & - & 100 & - & - & 83 & - & - & 17 \\
\hline 48 & 43 & - & 17 & - & - & 100 & - & - & 89 & - & - & 16 \\
\hline 60 & 36 & - & 17 & - & - & 97 & - & - & 88 & - & - & 16 \\
\hline
\end{tabular}

excluding the $19.6 \%$ who dropped out at various times during the first 6 months and whose average weight loss at 5 months was $8.4 \%$.

Follow-up weights for the Trevose program were obtained on $58 \%$ of members who had dropped out. These members did not differ from those who were not contacted in terms of age, baseline weight or weight losses at 1,6 , and 12 months of treatment. Their average net weight loss (weight below baseline values) 47.1 months after leaving the program was $4.7 \pm 1.1 \%$ or $4.5 \pm 2.3 \mathrm{~kg}$. The length of follow-up was not related to the size of the net weight loss.

Three major predictors of weight loss, as determined by regression analysis, accounted for $60 \%$ of the variance in weight loss in $\mathrm{kg}(F(3,162)=48.3$; $P<0.001)$, and $47 \%$ of the variance in percentage weight loss $(F(3,162)=81.7 ; P<0.001)$. The predictors were months in treatment $(\beta=0.51 ; P<0.001)$, weight loss during the first month $(\beta=0.30 ; P<.001)$ and initial BMI $(\beta=0.27 ; P<0.001)$. The higher the initial BMI, the greater the weight loss.

\section{Discussion}

The Trevose Behavior Modification Program is a surprisingly effective weight control program, particularly when considered in the light of its minimal costs.

The results of the Trevose program are difficult to compare with those of other programs because of its far greater duration of treatment. Thus, of the six programs with follow-up periods of at least $4 \mathrm{y}$, treatment averaged only 16.4 weeks in duration..$^{5-10}$ Four-year follow-up of these programs showed an average net weight loss of $1.9 \mathrm{~kg}$ compared to $4.5 \mathrm{~kg}$ for Trevose drop-outs contacted at follow-up. Weights for the Trevose subjects may be somewhat more reliable than those of the other six studies, since they were obtained on a substantial proportion of subjects (58\%) who were representative of those not contacted. The representativeness of the subjects of the other studies is not known.
In the present study, the largest percent of weight loss, $20 \%$, did not occur until 30 months of treatment, emphasizing again the advantages of long-term treatment. By contrast, maximum weight loss in traditional behavioral programs consistently occurs at 6 months. ${ }^{17}$

The high drop-out rate by the end of the fifth year of treatment calls for caution in interpreting the results. Nevertheless, the drop-out rate at earlier points in treatment is comparable to other treatment studies. It may be helpful to compare the Trevose results with those of a recent, large, $2 y$ controlled trial of the lipase inhibitor Orlistat. ${ }^{18}$ This study enrolled 1187 persons who were somewhat heavier $(\mathrm{BMI}=36.5)$ than the Trevose subjects (BMI of men $=35.1$, of women $=33.2$ ) and greater weight favors greater weight loss. After a 4 week placebo run-in period, comparable to the Trevose 5-week trial period, all subjects received a diet, behavioral consultations and either Orlistat or placebo. Subjects remaining in treatment were comparable in the two studies: at $1 \mathrm{y}$ Trevose $62 \%$, Orlistat $69 \%$, placebo $57 \%$; at $2 \mathrm{y}$, Trevose $47 \%$, Orlistat (drug and placebo) $43 \%$.

During the $2 \mathrm{y}$ of treatment, Trevose subjects lost far more weight. Table 1 shows that at $1 \mathrm{y}$ the mean weight loss for Trevose (19\%) was twice that for Orlistat $(9 \%)$ or placebo $(6 \%)$. At $2 y$ the weight loss for Trevose (19\%) approached three times that for Orlistat (8\%) and placebo (6\%). At $1 \mathrm{y}$, the percentage of subjects who lost at least $10 \%$ of their initial weight at Trevose was $97 \%$ compared to 39\% for Orlistat and $25 \%$ for placebo. At 2 y $94 \%$ of Trevose subjects had lost $10 \%$ of their initial weight compared to $34 \%$ for Orlistat and $18 \%$ for placebo. The Orlistat study terminated at two years, while weight losses of Trevose subjects in treatment remained substantial (Table 1).

The self-help format of the Trevose program does not appear to be responsible for its success, which was far greater than that of two other self help programs for obesity: Take Off Pounds Sensibly (TOPS) ${ }^{19}$ and Overeaters Anonymous. ${ }^{20}$ A study of 21 TOPS chapters in the Philadelphia area revealed that the average member lost $6.8 \mathrm{~kg}$ but fewer persons remained in treatment than in Trevose: $53 \%$ survived for $1 \mathrm{y}$ and 
$30 \%$ for $2 \mathrm{y}^{19}$ Overeaters Anonymous does not attempt weight loss. ${ }^{20}$

The content of the Trevose program does not seem different from that of most other behavioral weight control programs. What is different is its provision for treatment on a continuing basis. As noted above, behavior therapy appears effective as long it is used: at $2 \mathrm{y}$ weight loss was $19 \%$ of initial weight and at $5 \mathrm{y}$ it was $17 \%$.

The behavior modification component of the program contains no unique features. It relies on oldfashioned behavior therapy; little has changed since it was first introduced in 1971 in the early days of the field. At the time that one of the authors (AJS) and Henry Jordan were helping David Zelitch implement it at Trevose, it was tested in another setting: the 21 TOPS chapters in the Philadelphia area noted earlier. As part of a larger controlled trial, the leaders of four TOPS chapters were taught the principles of behavior modification and trained with the help of a behavioral weight loss manual. Their results over a period of 12 weeks were compared with those of four matched TOPS chapters that continued their standard program. The behavioral program decreased drop-out rate, both during treatment and at a 9-month followup, to $41 \%$ compared to $67 \%$ for the standard program. Weight loss at the end of the behavioral program was $0.9 \mathrm{~kg} v s$ a gain of $0.3 \mathrm{~kg}$ in the standard program. ${ }^{21}$ The difference between the results of the TOPS and the Trevose behavioral programs could not have been more striking, leading us to look beyond the program's content for an explanation of its effectiveness.

It is, of course, possible that these results may be due to particular characteristics of the group examined here. However, there are few restrictions on who can apply and the applicants do not appear to differ from the vast majority of persons seeking behavioral treatment for obesity. Even the predictors of weight loss in Trevose and other programs do not differ. The amount of weight lost during the first month of treatment, the duration of treatment and the initial BMI, highly predictive in the Trevose program, are also predictive in other programs reported in the literature. ${ }^{22}$ However, no other treatment program in the US has shown this level of long-term effectiveness, even in a specific population. These results provide preliminary support for the Trevose model of continuous care combined with self-help and strict behavioral contingencies.

The effective elements of the Trevose program appear to be its model of continuing care and its implementation.

First, the program tries to keep members in treatment indefinitely and helps to make this goal feasible. Obesity is presented as a life-long problem that requires life-long effort. There is no suggestion that, once the requisite behaviors are learned, the task is completed; they must be practised indefinitely. Successful members are recruited to serve as role models and teachers.
Second, one of the very few criteria for exclusion from Trevose is critical: no previous members are accepted. Applicants learn at their first encounter that this is a once in-a lifetime opportunity. As the Trevose Leaders' Manual makes clear, 'this is a last chance program'. ${ }^{23}$

Third, prospective candidates learn about Trevose primarily from satisfied members who describe the expectations. They arrive highly motivated and know the rules.

Fourth, the rules are in force from the beginning, with the critical requirement that members complete the 5 -week trial of treatment and lose $15 \%$ of goal weight. This trial period is of great importance, for it introduces members to the practical aspects of the program and, particularly, its non-negotiable requirements.

Fifth, members know from the beginning that failure to meet attendance and weight loss goals is grounds for dismissal. The message is, 'We take this work very seriously and expect that you will'.

These circumstances appear to be responsible for the successful implementation of the Trevose program - its simple and unambiguous contingencies: if members do not attend or if they fail to meet their weight loss goal, they are out and cannot come back. No bargaining, no second chances. This implementation and the opportunity for continuing care are the hallmarks of this successful program.

The time is ripe for replication and additional testing of the Trevose model on a large scale. Such application, by both state and country health departments, would have many benefits. It would bring lowcost weight loss to large populations and would facilitate studies of the mechanisms of the Trevose program that might further increase its effectiveness.

\section{Acknowledgements}

The authors are grateful to Theresa Chilton, Louise Fisher, Mildred Gamble, Sue Hirsch, and Arlene Robinson, volunteers at the Trevose Behavior Modification Program, for their valuable administrative assistance.

\section{References}

1 Perri MG. The maintenance of treatment effects in the longterm management of obesity. Clin Psychol Sci Pract 1998; 5: $526-543$

2 Connolly HM, Crary JL, McGoon MD, Hensrud DD, Edwards BS, Edwards WD, Schaff HV. Valvular heart disease associated with fenfluramine-phentermine. N Engl J Med 1997; 337: $581-588$.

3 Devereux RB. Appetite suppressants and valvular heart disease. $N$ Engl J Med 1999; 339: 765-767.

4 Williamson DF. Pharmacotherapy for obesity. JAMA 1999; 21: $278-280$

5 Stunkard AJ, Penick SB. Behavior modification in the treatment of obesity: the problem of maintaining weight loss. Arch Gen Psychol 1979; 36: 801-806.

6 Graham LE, Taylor CB, Hovell MF, Siegal W. Five-year follow-up to a behavioral weight-loss program. J Consult Clin Psychol 1983; 51: 322-323. 
7 Stalonas PM, Perri MG, Kerzner AB. Do behavioral treatments of obesity last? A five-year follow-up investigation. Addict Behav 1984; 9: 175-183.

8 Murphy JK, Bruce BK, Williamson DA. A comparison of measured and self-reported weights in a 4-year follow-up of spouse involvement in obesity treatment. Behav Ther 1985; 16: $524-530$

9 Wadden TA, Sternberg JA, Letizia KA, Stunkard AJ, Foster GD. Treatment of obesity by very low calorie diet, behavior therapy, and their combination: a five-year perspective. Int $J$ Obes 1989; 13: 39-46.

10 Wadden TA, Frey DL. A multicenter evaluation of a proprietary weight loss program for the treatment of marked obesity: a five-year follow-up. Int J Eat Disord 1997; 22: 203-212.

11 Klein ML, Wing RR, McGuire MT, Seagle HM, Hill JO. A descriptive study of individuals successful at long-term maintenance of substantial weight loss. Am J Clin Nutr 1997; 66: 239-246.

12 Bjorvell H, Rossner S. Long term treatment of severe obesity: four year follow up of results of combined behavioural modification programme. $\mathrm{Br}$ Med $J$ 1985; 291: 379-382.

13 Bjorvell $\mathrm{H}$, Rossner S. A ten year follow-up of weight change in severely obese subjects treated in a behavioural modification-like program. Int J Obes 1990; 14(Suppl 2): 88.

14 Bennett GA. Behavior therapy for obesity: a quantitative review of the effects of selected treatment characteristics on outcome. Behav Ther 1986; 17: 554-562.
15 Perri MG, Nezu AM, Patti ET, McCann KL. Effect of length of treatment on weight loss. J Consult Clin Psychol 1989; 57: $450-452$

16 Metropolitan Life Insurance Company. New weight standards for men and women. Stat Bull Metrop Insur Co. 1959; 40: 1 .

17 Jeffery RW, Drewnowski A, Epstein LH, Stunkard AJ, Wilson GT, Wing RR, Hill DR. Long term maintenance of weight loss: current status. Health Psychol 2000; 19(Suppl): 5-16.

18 Davidson MH, Hauptman J, DiGirolamo M, Foreyt JP, Halsted CH, Heber D, Heimburger DC, Lucas CP, Robbins DC, Chung J, Heymsfield SB. Weight control and risk factor rediction in obese subjects treated for $2 \mathrm{y}$ with Orlistat: a randomized controlled trial. JAMA 1999; 281: 235-242.

19 Garb JR, Stunkard AJ. Effectiveness of a self-help group in obesity control. Arch Int Med 1974; 134: 716-720.

20 Anonymous. Overeaters anonymous. JAMA 1984; 251: $468-469$.

21 Levitz LS, Stunkard AJ. A therapeutic coalition for obesity: behavior modification and patient self-help. Am J Psychiat 1974; 131: 423-427.

22 Wilson GT. Behavioral and psychological predictors of treatment outcome in obesity. In Allison DB, Pi-Sunyer FX (eds). Obesity treatment. New York: Plenum Press, 1995, pp $183-189$.

23 Trevose Behavior Modification Program. Leaders' manual, unpublished manuscript, 1990. 
Copyright $\odot 2003$ EBSCO Publishing 